\title{
Short-Term Results of Canaloplasty Surgery for Primary Open-Angle Glaucoma in Japanese Patients
}

\author{
Kazuya Fujita Kiyotaka Kitagawa Yoshiki Ueta \\ Tomoko Nakamura Akio Miyakoshi Atsushi Hayashi \\ Department of Ophthalmology, Graduate School of Medicine and Pharmaceutical \\ Sciences, University of Toyama, Toyama, Japan
}

\section{Key Words}

Canaloplasty $\cdot$ Primary open-angle glaucoma $\cdot$ Intraocular pressure $\cdot$ Complications

\begin{abstract}
Purpose: To report surgical results of canaloplasty surgery for primary open-angle glaucoma (POAG) in Japanese patients.
\end{abstract}

Methods: Eleven eyes of 9 POAG patients underwent canaloplasty surgery at Toyama University Hospital. Three eyes of 3 patients underwent canaloplasty alone and 8 eyes of 6 patients underwent canaloplasty combined with cataract surgery. Canaloplasty was performed with a 10-0 polypropylene tensioning suture and an $\mathrm{iTrack}^{\mathrm{TM}} 250 \mathrm{~A}$ microcatheter. All patients were followed up for 12 months. Changes in intraocular pressure (IOP) and postoperative complications were examined.

Results: Mean preoperative IOP was $23.4 \pm 5.5 \mathrm{~mm} \mathrm{Hg}$. Mean number of antiglaucoma drops was $2.8 \pm 0.6$ before canaloplasty and decreased to $1.2 \pm 0.8$ at 12 months after canaloplasty $(p<0.01)$. Mean IOP decreased postoperatively, being $13.7 \pm 2.8 \mathrm{~mm} \mathrm{Hg}$ at 1 month, $12.8 \pm 3.5 \mathrm{~mm} \mathrm{Hg}$ at 3 months, $14.0 \pm 4.4 \mathrm{~mm} \mathrm{Hg}$ at 6 months, and $15.0 \pm 4.1$ $\mathrm{mm} \mathrm{Hg}$ at 12 months. The most frequent postoperative complication was mild hyphema (45.5\%), which disappeared within 14 days after surgery.

Conclusions: Canaloplasty may be an alternative surgery for POAG patients to reduce IOP to a value of approximately $15 \mathrm{~mm} \mathrm{Hg}$.

\section{Introduction}

Canaloplasty is a new nonpenetrating glaucoma surgery that is expected to increase physiological aqueous outflow from the anterior chamber through the trabeculoDescemet's window into Schlemm's canal $[1,2]$. Using the flexible iTrack ${ }^{\mathrm{TM}} 250 \mathrm{~A}$ microcatheter (iScience Interventional, Menlo Park, Calif., USA), designed especially for 
canaloplasty, 10-0 polypropylene tensioning suture is installed into Schlemm's canal circumferentially. Canaloplasty is not widely performed in Japan. We studied the surgical results of canaloplasty surgery for Japanese primary open-angle glaucoma (POAG) patients.

\section{Case Report}

Nine patients (11 eyes) of POAG treated at Toyama University Hospital between December 2008 and June 2009 were included in this study. Three eyes of 3 patients underwent canaloplasty alone and 8 eyes of 6 patients underwent canaloplasty combined with phacoemulsification/aspiration and intraocular lens implantation (PEA + IOL).

This study was approved by the Institutional Review Board of the University of Toyama. Written informed consent was obtained from each of the patients after they were provided with sufficient information about the procedures.

The mean age of the patients was $71.7 \pm 8.5$ years (mean \pm standard deviation). The mean preoperative intraocular pressure (IOP) was $23.4 \pm 5.5 \mathrm{~mm} \mathrm{Hg}$. The mean number of antiglaucoma drops used before canaloplasty was $2.8 \pm 0.6$.

All patients who underwent canaloplasty alone had undergone cataract surgery previously. Surgical techniques were as follows. Briefly, after limbal conjunctival peritomy, a superficial parabolic flap approximately $4 \mathrm{~mm}$ wide and $5 \mathrm{~mm}$ long was created at the 12 o'clock limbus. Then a deep flap was created within the margin of the superficial flap. PEA + IOL were performed from beneath the superficial flap. The deep flap was excised and a trabeculo-Descemet's window was formed. After injection of viscoelastic material into the ostia of Schlemm's canal, 10-0 polypropylene tensioning suture was installed using an iTrack $250 \mathrm{~A}$ microcatheter. The superficial flap and the conjunctiva were closed in a watertight manner. The IOP was measured at $1,3,6$, and 12 months postoperatively. Mean IOPs were $13.7 \pm 2.8 \mathrm{~mm} \mathrm{Hg}$ at 1 month, $12.8 \pm 3.5 \mathrm{~mm} \mathrm{Hg}$ at 3 months, $14.0 \pm 4.4 \mathrm{~mm} \mathrm{Hg}$ at 6 months, and $15.0 \pm 4.1 \mathrm{~mm} \mathrm{Hg}$ at 12 months (fig. 1). Statistical analysis was carried out by a paired test and Dunn's multiple comparison analysis. All postoperative mean IOPs were significantly decreased compared to the preoperative IOP of $23.4 \pm 5.5 \mathrm{~mm} \mathrm{Hg}(\mathrm{p}<0.001$ or $\mathrm{p}<0.01)$. Fig. 2 shows an image of the anterior segment optical coherence tomography (CASIA; Tomey Corporation, Nagoya, Japan), which indicated the tensioned and dilated Schlemm's canal (arrows) at 12 months after canaloplasty surgery. A KaplanMeier survival model was used for cumulative probability of qualified success with or without medications (fig. 3). The qualified success rate of an IOP of 21, 18, and $16 \mathrm{~mm} \mathrm{Hg}$ or less at 12 months was $81.8,54.5$, and $54.5 \%$, respectively (fig. 3 ). The mean postoperative number of antiglaucoma drops was significantly reduced to $1.2 \pm 0.8(\mathrm{p}<0.01)$. Postoperative complications are shown in table 1 . The most frequent postoperative complication was mild hyphema (45.5\%), which disappeared within 14 days after the surgery without detrimental effect.

\section{Discussion}

We have previously reported on the feasibility of canaloplasty in Japan [3]. Grieshaber et al. [4] reported the long-term outcomes of canaloplasty for POAG in black African patients. Their mean postoperative IOP was $15.4 \pm 5.2 \mathrm{~mm} \mathrm{Hg}$ at 12 months. We showed a similar mean postoperative IOP of $15.0 \pm 4.1 \mathrm{~mm} \mathrm{Hg}$ at 12 months after canaloplasty. Because this was a retrospective study, we could show only qualified success rates. Canaloplasty reduced the mean postoperative number of antiglaucoma drops and it may be suitable to reduce the IOP to a value of approximately $15 \mathrm{~mm} \mathrm{Hg}$.

No serious intraoperative or postoperative complications were experienced in our study. Mild hyphema was the most frequent postoperative complication (45.5\%). During the installation of the iTrack 250A microcatheter into Schlemm's canal, mild bleeding 
from the trabecular tissue into the anterior chamber was frequently found.

Microperforation of the trabecular meshwork might occur during the catheterization.

Koch et al. [5] reported that anterior chamber hemorrhage with hyphema was found in 15 of 21 eyes $(71.4 \%)$ on day 1 after canaloplasty, and the eyes without hyphema showed higher IOP than those with hyphema. It is possible that microperforation may be one of the mechanisms of IOP reduction by canaloplasty surgery.

Although long-term results of canaloplasty have not been clarified yet, canaloplasty may be an alternative method for Japanese patients with POAG when the desired pressure is around $15 \mathrm{~mm} \mathrm{Hg}$.

\section{Disclosure Statement}

The authors have no financial/conflicting interests to disclose.

Table 1. Postoperative complications in canaloplasty surgery

\begin{tabular}{ll} 
Hyphema & $5 / 11$ eyes \\
Intraocular pressure spike $(>30 \mathrm{~mm} \mathrm{Hg})$ & $2 / 11$ eyes \\
Descemet's membrane detachment & $1 / 11$ eyes \\
Prolapse of $10-0$ prolene into anterior chamber & $1 / 11$ eyes \\
Mild vitreous hemorrhage & $1 / 11$ eyes \\
\hline
\end{tabular}

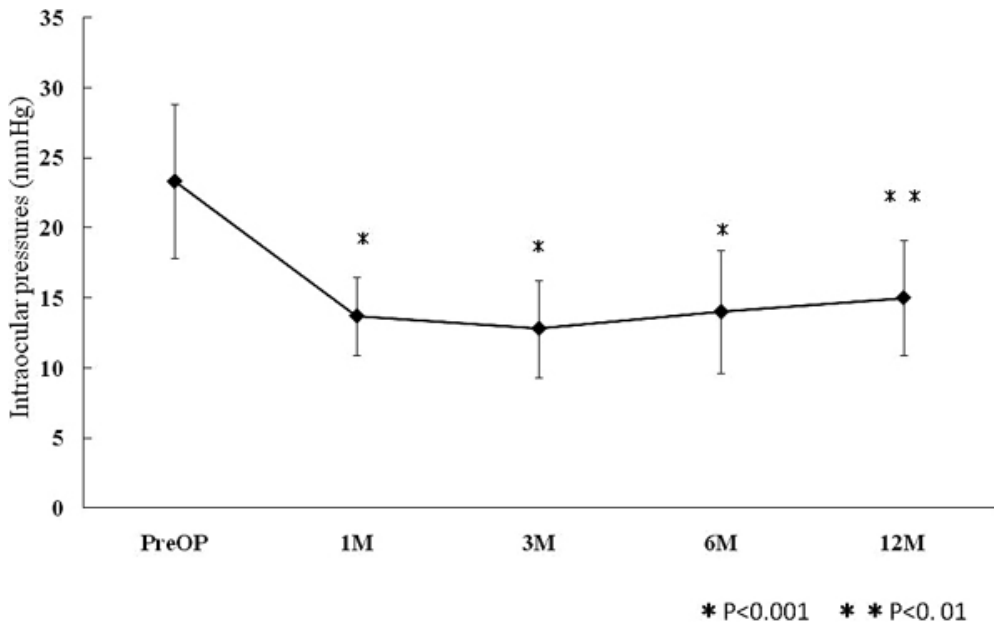

Fig. 1. Changes of mean IOP after canaloplasty surgery. 


\begin{tabular}{l|l|l|l} 
Case Reports in & $\begin{array}{l}\text { Case Rep Ophthalmol 2011;2:65-68 } \\
\text { DOI: 10.1159/000324808 }\end{array}$ & $\begin{array}{l}\text { Published online: } \\
\text { February 14, 2011 }\end{array}$ & $\begin{array}{l}\text { ○ 2011 S. Karger AG, Basel } \\
\text { ISSN 1663-2699 } \\
\text { www.karger.com/cop }\end{array}$ \\
\hline
\end{tabular}

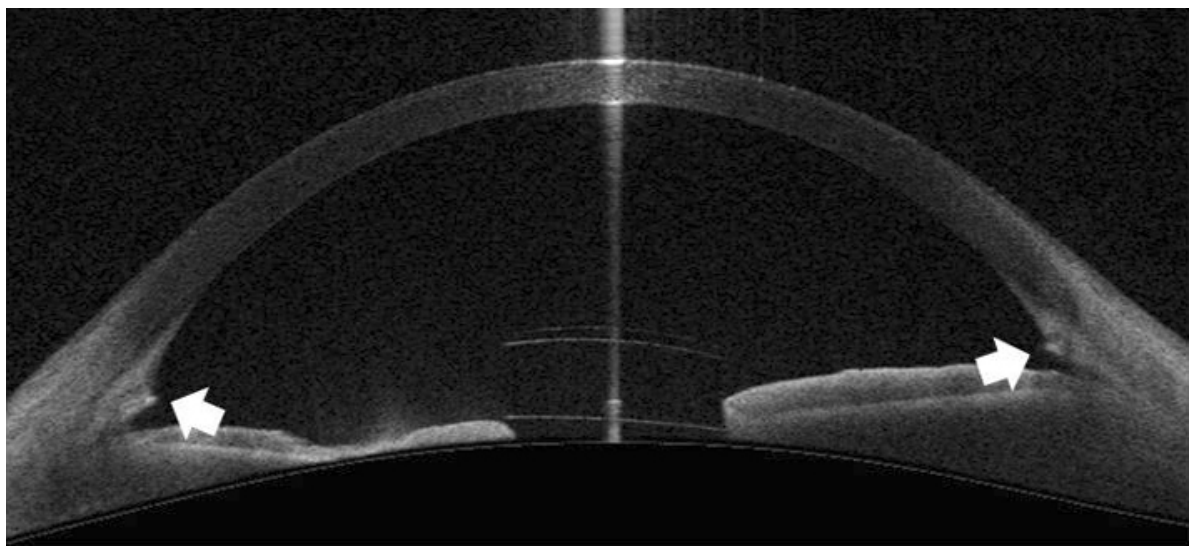

Fig. 2. A horizontal image of anterior segment optical coherence tomography of a patient 12 months after canaloplasty surgery. Arrows show the tensioned and dilated Schlemm's canal.

(\%)

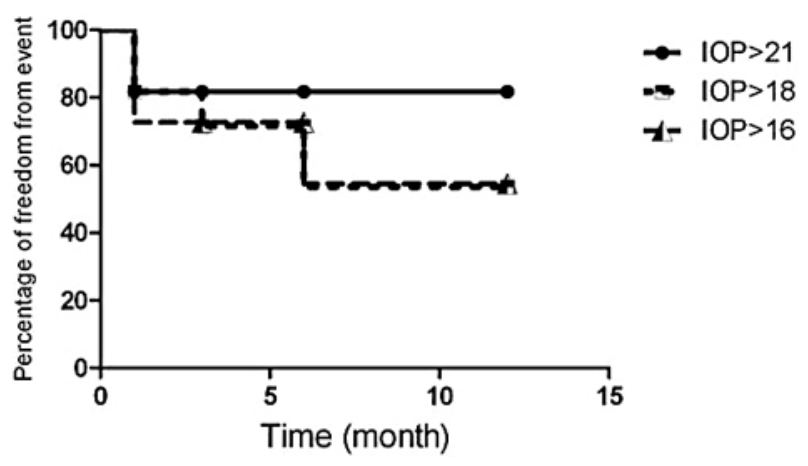

Fig. 3. Kaplan-Meier analysis for IOP.

\section{References}

1 Lewis RA, von Wolff K, Tetz M, et al: Canaloplasty: circumferential viscodilation and tensioning of Schlemm's canal using a flexible microcatheter for the treatment of open-angle glaucoma in adults: interim clinical study analysis. J Cataract Refract Surg 2007;33:1217-1226.

-2 Shingleton B, Tetz M, Korber N: Circumferential viscodilation and tensioning of Schlemm canal (canaloplasty) with temporal clear corneal phacoemulsification cataract surgery for open-angle glaucoma and visually significant cataract: one-year results. J Cataract Refract Surg 2008;34:433-440.

3 Kitagawa K, Hayashi A: Clinical trial of a flexible microcatheter iTrack 250A for canaloplasty. Folia Japonica de Ophthalmologica Clinica 2009;2:924-928.

-4 Grieshaber MC, Pienaar A, Olivier J, Stegmann R: Canaloplasty for primary open-angle glaucoma: long-term outcome. Br J Ophthalmol 2010;94:1478-1482.

5 Koch JM, Heiligenhaus A, Heinz C: Canaloplasty and transient anterior chamber haemorrhage: a prognostic factor? Klin Monbl Augenheilkd 2010, Epub ahead of print. 